(C) The Author(s), 2021. Published by Cambridge University Press on behalf of The Hegel Society of Great Britain. This is an Open Access article, distributed under the terms of the Creative Commons Attribution licence (http://creativecommons.org/licenses/by/4.0/), which permits unrestricted re-use, distribution, and reproduction in any medium, provided the original work is properly cited.

\title{
Purposiveness, Intelligibility and Kant's Scepticism: Reconsidering Ng's Account of Hegel's Response to Kant
}

\section{Karen Koch}

Hegel's integration of the concept of Life ${ }^{1}$ in the Logic has long been disputed and rejected by many scholars. The most common objection was that it seemed counterintuitive to integrate an empirical phenomenon such as Life into a Logic that, in fact, ought to present an immanent development of pure concepts. Hegel was often accused of bringing empirical considerations into his Logic in order to develop his logical account of Life. ${ }^{2}$ Consequently, there has been a great discussion about the question as to whether a Logic is an appropriate place for this concept - a discussion that did not occur with respect to other categories in Hegel's Logic. Now, in contemporary literature on Hegel, there is a surge of genuine interest in Hegel's logical account of Life, accompanied by the insight that the concept of Life plays an important and indispensable role in Hegel's philosophy. However, what this role is precisely is a controversial issue.

In her book Hegel's Concept of Life. Self-Consciousness, Freedom, Logic, Karen $\mathrm{Ng}$ develops a refreshing and highly sophisticated account of the role of Life in Hegel's philosophy and especially in Hegel's Logic. Ng's central aim is to show that Life is constitutive not only of the activities of reason and thought, but also of Hegel's Idealism itself (4). The term 'constitutive' is to be taken literally here: According to $\mathrm{Ng}$, reason does not have an analogous structure to Life: rather, 'reason is a dynamic, living activity in constant development' (3). Likewise, $\mathrm{Ng}$ identifies a speculative subject-object identity as the essential feature of Hegel's Idealism that in turn is grounded in the core structure of Life itself, not just in a structure analogous to that of Life. As such, $\mathrm{Ng}$ takes Hegel's account of Life to be central for the understanding of the absolute method and therefore for the project of Hegel's Logic itself.

This is a broad and systematically very far-reaching thesis and is defended by drawing on three 'entangled' claims in particular:

The first one is rather general, claiming that the main ideas or the 'core tenets' of Hegel's philosophy stem from his discussion of the 'purposiveness theme' Kant 


\section{Purposiveness, Intelligibility and Scepticism}

introduced in his Critique of Judgement (5). One specification of the claim is that Hegel's account of the concept of the Concept is informed by this discussion, and especially by Kant's conception of inner purposiveness. $\mathrm{Ng}$ emphasizes the importance of inner purposiveness for Hegel's concept of the Concept in two ways: by arguing that Hegel adopts the Kantian claim that the principle of purposiveness is the condition for applying logic to nature, and by showing the deficiencies of Kant's own treatment of this claim. I will return to Ng's reading of Kant in the first part of this paper.

The second claim is the speculative identity thesis. This claim states that there is an identity of object and subject, and what makes this identity speculative is 'the identity and opposition between life and self-consciousness' (9). According to Ng, Hegel develops this thesis in his discussion of Schelling and Fichte in the Differenzschrift and elaborates on it in the Phenomenology of Spirit and the Science of Logic. The Logic presents a version of this thesis in what $\mathrm{Ng}$ calls the 'doubling of the idea' (275).

The relevance $\mathrm{Ng}$ attaches to the claim of the speculative subject-object identity, which she takes to be tantamount to the self-consciousness-life identity, is indeed noteworthy. Elaborating on this thesis, according to $\mathrm{Ng}$, not only presents a common thread running through Hegel's whole philosophical career. Unfolding this thesis is also what the absolute method of the Logic consists in, which she understands as the 'ongoing dialectic between life and cognition' (279). This claim illustrates that on Ng's reading another core tenet of Hegel's philosophy, his account of self-consciousness, centres on the purposiveness theme inherited from Kant. In fact, according to $\mathrm{Ng}$, Hegel develops Kant's claim that the principle of purposiveness is a necessary condition for judgement into a claim about life being constitutive for self-consciousness (8).

The third of the entangled claims consists in her reading of Hegel's Subjective Logic as his own 'Critique of Judgment' (9). This part of the Logic, according to $\mathrm{Ng}$, offers a positive account of the constitutive role Hegel attributed to Life in his critical interaction with Kant. The main claim is that the form of Life is the ground and presupposition of Hegel's theory of concepts and judgements as expounded in the section of the Logic entitled 'Subjectivity'. Judgements 'are measured according to their ability or inability to express the unity displayed by life, or the unity of what Kant called a natural purpose' (166).

While joining those interpreters who capture Hegel's thought by emphasizing the influence of some key Kantian concepts for the former's own philosophy, $\mathrm{Ng}$ offers an exciting new take on this. Instead of approaching Hegel's philosophy through the theme of apperception or through the conception of an intuitive understanding, she reads Hegel's philosophy, and particularly his Logic, through the lens of the theme of purposiveness.

I think that the approach to Hegel via the purposiveness theme is promising and I think $\mathrm{Ng}$ is right in taking it to be central for a reading of Hegel's Logic. 


\section{Karen Koch}

Undoubtedly, $\mathrm{Ng}$ offers an illuminating and substantial reading of the logical role of Life within the Logic. However, my main worry is that she might be giving too much weight to the theme of inner purposiveness. There are three related points here: firstly, it is not entirely clear how her reading relates to the other two approaches, which she uses briefly to present her own position, and what role other Kantian key concepts (i.e. apperception and intuitive understanding) play in Hegel (part I). Secondly, one could also offer a different reading of Kant that avoids the problems raised by Ng's interpretation of Kant and does not draw on the concept of inner purposiveness in the strong way $\mathrm{Ng}$ suggested (part II). Thirdly, with respect to Hegel's response to Kant's scepticism (part III), it would also not be entirely unjustified to ask whether she is not giving too much weight to the thesis that Life, i.e. inner purposiveness, 'opens up the space of reasons' $(234,281)$. To be concrete, it is not clear whether this can be taken to be an exhaustive response to Kant's scepticism.

\section{The relation of $\mathrm{Ng}$ 's account to other approaches}

I'd like to begin with a discussion of Ng's general reading of the Logic. This might be a minor point about the manner of presentation, but one worth elaborating on nonetheless. $\mathrm{Ng}$ draws on the two other approaches analysing Hegel via Kant, i.e. those that prioritize the theme of apperception and the concept of the intuitive understanding respectively. In fact, she points out that she aims to preserve their advantages while avoiding their disadvantages (11), but she does not elaborate on this later on. ${ }^{3}$ Thus, the question of the exact relation to these approaches remains.

Looking at the textual evidence, it is not immediately obvious that all of Hegel's core tenets are focused on the theme of purposiveness. Hegel obviously refers to Kant's transcendental apperception in the introductory parts of the concept of the Concept, praising Kant for having developed the thought of the synthetic unity of apperception that he takes to be central for his own account of concept of the Concept:

It is one of the profoundest and truest insights to be found in the Critique of Pure Reason that the unity which constitutes the essence of the concept is recognized as the original synthetic unity of apperception, the unity of the 'I think', or of self-consciousness (WL: 515/12:17f.) ${ }^{4}$.

Thus, it is somewhat surprising that $\mathrm{Ng}$ clearly frames her approach to the Subjective Logic by the purposiveness theme. She opens her discussion of the Subjective Logic by underlining the importance of the Idea of Life as presupposition of Hegel's theory of Judgement (165f.) and by claiming that the three 


\section{Purposiveness, Intelligibility and Scepticism}

moments constituting the concept of the Concept (i.e. universal, particular and individual) reflect the defining three moments of a natural end (163). At the beginning of the Subjective Logic, however, Hegel is concerned with the speculative relation of the particular to the universal that is expressed in Kant's concept of the I, and this relation does not seem to be one of kind and species.

Now, $\mathrm{Ng}$ would likely argue that the passages in which Hegel refers to the apperception theme in Kant must be read through the lens of the purposiveness theme in Hegel, since the Idea (and especially the Idea of Life) serves as ground of all the other thought determinations 'insofar as it secures their mode of realization' (257), which in turn justifies her interpretive approach here. Along these lines she already takes Kant to hint at another theory of concepts (48f.) and of judgements in the third Critique (61f.), that actually grounds his theory of judgement in the first Critique. However, the question of the right balance between the apperception approach and her own remains. Are these complementary views or does she modify the apperception view in such a way that it is not tenable anymore ${ }^{5}$

Likewise, as $\mathrm{Ng}$ mentions herself (16), Hegel does praise Kant for developing the thought of an intuitive understanding, claiming that it is the conception of an intuitive understanding being able to grasp organic unity:

The power of reflective judgment is credited with the principle of an intuitive understanding, in which the particular, which is supposed to be contingent with respect to the universal $[\ldots]$ and not to be derivable from it, is determined by this very universal - something that is said to be experienced in the products of art and of organic nature. (EL: $\$ 55 / 20: 93$ )

And Hegel continues:

The Critique of the Power of Judgment is distinguished by the fact that in it Kant has articulated the representation, indeed, the thought of the idea. The representation of an intuitive understanding, of inner purposiveness, etc., is the universal simultaneously thought as concrete in itself (EL: \55R/20:93).

$\mathrm{Ng}$ dismisses the approach to Hegel via the intuitive understanding by noting that it leaves undertheorized the reciprocal dependency and speculative identity of subject and object, thus between intuitive understanding and perceived object (15). As such, this approach cannot account for the purposiveness of the subject itself (16). However, since $\mathrm{Ng}$ discusses the structure of inner purposiveness-understood as synonymous with organic unity - and the logical role of it in Hegel's Logic, the question of how exactly $\mathrm{Ng}$ relates to this approach remains. Her idea seems to be the following: The subject-object relation reflected in the relation of intuitive understanding and perceived object itself needs to be grounded in 


\section{Karen Koch}

inner purposiveness. This way, her approach might incorporate the intuitive understanding approach in a modified way. However, it is not entirely clear where exactly she locates the intuitive understanding approach within her own interpretation.

I would now like to turn to the first of the two main worries that challenge her account of the Kantian inheritance in Hegel. Ng underlines that Hegel only deals with life in the logical sense in the Logic and that he articulates the logical, a priori role that Life is supposed to play within it. According to $\mathrm{Ng}$, Hegel's concern is not about whether there is in fact life in nature (quid facti), but about the legitimate use of the concept of Life in the Logic, which she understands as an a priori project dealing with constitutive concepts (quid juris) (7). ${ }^{6}$ However, the thesis of the legitimate use of the concept of Life is anchored in a specific interpretation of the Kantian legacy, one that I would like to challenge in what follows.

\section{The Kantian legacy}

Hegel praises Kant explicitly for reintroducing the difference between external and internal purposiveness, and especially for 're-awakening' the Idea and, in particular, the Idea of Life by drawing on the conception of inner purposiveness, which he takes to be of Aristotelian origin (EL: $\$ 204 / 20: 210)$. Thus, it is a promising and not that surprising approach to draw on the purposiveness theme in Kant and specifically to use the conception of inner purposiveness as the starting point of a reading of Hegel's Logic.

In order to develop her thesis of the logical role that Life is supposed to play within Hegel's Logic, Ng draws on this Kantian background. She aims to show that Hegel develops further the Kantian thought that the principle of purposiveness of nature is the condition for applying logic in general and judgements in particular to nature. I will focus on two lines of argument in Kant's discussion of purposiveness that are relevant to Ng's reading of Hegel.

First, $\mathrm{Ng}$ argues that purposiveness serves 'the function of an enabling, empowering condition for judgment' (61). The background for this first line of argument is the Transcendental Analytic in Kant's Critique of Pure Reason. Here the question arises what exactly the Transcendental Deduction, and with it the Analytic of Principles, is supposed to establish. $\mathrm{Ng}$ concurs with the interpretation of the Transcendental Analytic according to which the argument in the Transcendental Analytic leaves open the possibility of empirical disorder-or what $\mathrm{Ng}$, following Henry Allison, calls 'empirical chaos' in nature (32f.). The argument in the Transcendental Analytic establishes transcendental laws of nature but does not account for the uniformity and regularity of nature. Thus, it neither establishes that the same causes have the same effects, nor does it establish that there are natural things that could be ordered under types, species and genera. Now, if there 


\section{Purposiveness, Intelligibility and Scepticism}

were not such a kind of regularity in nature, then we would not be able to engage in inductive reasoning. In particular, we would not be able to apply reflective judgements, through which we think the particular as contained under a universal. We would not be able to do so, because there simply would be no type-token relations. Given this setup, the introduction of the transcendental but regulative principle of purposiveness is the introduction of the presupposition that there be such a form of regularity in nature and that this form of regularity in nature fits our cognitive powers. Following $\mathrm{Ng}$, this principle provides the 'ground-level enabling condition' (46) under which we can apply reflective judgement in the first place. As such it 'opens up the horizon of intelligibility' (44) and is thus a reply to the threat of the empirical chaos the first Critique had left us with.

Second, $\mathrm{Ng}$ argues that the intentional designer-artifact model that informs Kant's presentation of the purposiveness theme fails to provide a good explanation for the purposiveness of nature as it is needed for the solution to the threat of empirical chaos (50). She takes up the Kantian definition of purpose and of purposiveness, claiming that purposiveness in general is the form of causality according to which a concept grounds the actuality and the form of an object (48). Within the Kantian framework, this claim is easy to understand: a concept has some kind of causal power because it is a designer who anticipated the concept before realizing the corresponding object of the concept. Now, $\mathrm{Ng}$ claims that this means that we judge there to be a designer who construed nature in such a way that it fits to our cognitive powers when we come to judge nature to be purposive. That is, according to $\mathrm{Ng}$, we judge nature to be an artifact. However, $\mathrm{Ng}$ argues that 'treating nature as if it were an artifact $[\ldots]$ runs counter to our sense that there is a crucial difference between artificial (created) and natural objects [...]' (49). In fact, there is a contradiction in judging natural objects to be artifacts and to be natural objects. Furthermore, she argues that according to Kant's philosophy, we do not know if such a designer-God exists. However, our very ability to form empirical judgements rests on this presupposition of an unknown God. According to $\mathrm{Ng}$, this makes 'the burden of a proof for his theory of judgment so incredibly high, and the theory itself so unwieldy, that we would be wise to simply reject it wholesale' (49f.). Thus, she concludes that ' $[\mathrm{t}]$ he artifact model [...] comes to look inherently unfit as an explanation of the purposiveness of nature' (50).

This conclusion is important for Ng's reading since it serves not only as the reason to reject the Kantian solution to the threat of empirical chaos, but also for considering another model of purposiveness to be the primary model (62) since it can solve the problem of empirical chaos in a better, non-contradictory way, and this is the principle of inner purposiveness. ${ }^{7}$ Thus, this conclusion motivates her interpretation of Hegel. However, $\mathrm{Ng}$ 's reading raises two main questions that challenge the strong conclusion she draws from her discussion of Kant's conception of purposiveness. 


\section{Karen Koch}

First, the reading of the Transcendental Analytic proposed by $\mathrm{Ng}$ is not uncontroversial. ${ }^{8}$ There are good reasons to hold a stronger reading of the Transcendental Analytic. That is, there are good reasons to hold that Kant already establishes the principle of uniformity within the Transcendental Analytic. If so, this changes the setting discussed in the introductions to the third Critique in a crucial way: there is in fact no empirical chaos, since the Transcendental Analytic has shown that nature is structured by empirical laws. However, this does not simultaneously mean that we are able to cognize these empirical laws. Consequently, the question the Transcendental Analytic has left us with and that Kant tries to answer in the introductions to the third Critique is the question about the cognizability of empirical laws and not the question whether there are empirical laws. Hence, the transcendental principle of purposiveness is a principle according to which we presuppose the cognizability of empirical laws of nature, but not one according to which we presuppose that there are empirical laws at all. Consequently, it is for this cognizability that we do not have a proof. This, however, is not a weakness of Kant's theory but a feature of it. As the finite beings we are, we are simply not able to know if nature is systematic in the way we think it is. There is thus no burden of a proof of the uniformity of nature itself to be shouldered by the purposiveness theme. Following this reading, the introduction of the principle of purposiveness introduced on the designer-artifact model no longer seems to be that problematic.

Now, these are two competing answers to the question that the Transcendental Analytic has left us with and, admittedly, there is also textual evidence for Ng's weaker reading. However, the remaining question is: Why not rely on the stronger reading of the Transcendental Analytic, if the weaker one gets in the end saddled with the need of refusing Kant's own solution? What are the reasons for not doing so?

Second, even though I agree with $\mathrm{Ng}$ that there is a contradiction in judging natural objects to be artifacts - and I also think Kant does-I do not think that this contradiction is at stake with respect to the transcendental principle of purposiveness. Thus, in my view $\mathrm{Ng}$ moves too quickly from judging the empirical laws of nature to be purposive for our cognitive powers to the claim that we must judge objects of nature to be purposive, or at least, this move needs more explanation.

In introducing the principle of transcendental purposiveness, Kant in fact claims that we must think of a designer who set up the laws of nature in such a way that it conforms to our cognitive powers. However, he does not claim that we must judge the objects of nature themselves to be purposive, i.e. to be artifacts. That is, he does not claim that we must think of a designer who created all things in nature. The latter would mean that we would have to judge all natural objects to be artifacts. However, the transcendental principle of purposiveness does not refer to things in nature per se but is only a principle according to which we judge nature to 


\section{Purposiveness, Intelligibility and Scepticism}

form a system of empirical laws that is purposive to our cognitive power. In applying this principle, we judge them to be connected in such a way that it fits our way of systematizing natural laws. It is in this respect that Kant still calls it a subjective and not an objective principle of purposiveness. The transcendental principle of purposiveness relates to the purposive relation between the subject and the object that is to be cognized, but not to the purposiveness of the object itself. Consequently, the transcendental principle of purposiveness

yields no inference to its usefulness for a real purposiveness in its products, i.e. for producing individual things in the form of systems: for the latter could always, as far as intuition is concerned, be mere aggregates and nevertheless be possible in accordance with empirical laws of nature interconnected with others in a system of logical division, without a concept specially instituted as the condition for their particular possibility [of the individual things, K.K.] having to be assumed, hence without a purposiveness of nature on its ground. In this way we see soils, stones, minerals etc., without any purposive form, as mere aggregates, but nevertheless as so related in the inner character and grounds for the cognition of their possibility that they are suitable for the classification of things in a system of nature under empirical laws yet do not display the form of a system in themselves (EE: 20:217).

Kant does obviously think that it does not follow from the claim, according to which we may legitimately apply the transcendental principle of purposiveness to nature, and thus assume that nature itself forms a system of empirical laws that conforms to our cognitive powers, that we must judge objects of nature themselves to be purposive, i.e., that we must judge them as being possible only through a purpose. Rather, according to Kant, there is a special class of natural objects that we must judge to be purposes. However, it is not determined a priori whether there is such a class of objects that we must judge to be purposes. Thus, the application of the principle of inner purposiveness to natural objects, by which we derive the concept of a natural end is occasioned through experience:

This principle, or its definition [of a natural end, K.K.], states: An organized product of nature is that in which everything is an end and reciprocally a means as well. Nothing in it is in vain, purposeless, or to be ascribed to a blind mechanism of nature. As for what occasions it, this principle is of course to be derived from experience, that is, experience of the kind 


\section{Karen Koch}

that is methodically undertaken and is called observation $(C J$ : $5: 376)$.

The assumption that we must judge certain objects of nature to be natural purposes only applies at this empirical level. Consequently, only here must we judge certain natural things to be purposes, which in turn creates the contradiction between natural object and artifact. So why or in what sense shall the contradiction in judging natural things to be artifacts already apply with respect to the transcendental principle of purposiveness?

I now turn to the second worry concerning Ng's account of Hegel's reception of Kantian scepticism with respect to inner purposiveness (part III). The worry is that Ng's interpretation of the logical role of Life in the Logic and especially the thesis that Life opens up the space of reasons seems to carry too large a burden of proof. As I already mentioned, her account provides an excellent account of the logical role of Life within Hegel's Logic. However, Ng's account seems to be too narrowly focused on the argument of this logical role, that, as I will argue now, leaves it open whether Ng's Hegel really has a rejoinder to Kant's scepticism with respect to natural purposiveness.

\section{Kant's scepticism: inner purposiveness and mechanism}

In order to employ Life as key to Hegel's Idealism as presented in the Logic, $\mathrm{Ng}$ argues that Life is constitutive for cognition in providing the horizon of intelligibility and of self-consciousness more generally. I think that $\mathrm{Ng}$ succeeds in showing the non-triviality and greater significance of these Hegelian claims. Ng shows that Life is not a presupposition in the sense that cognition needs to relate to any object in order to be possible, because to cognize simply means to cognize something. It rather is a presupposition in the sense that self-consciousness needs to relate to a specific (qualitative) kind of object, i.e. Life, that enables its own activity of judgement in the first place. This shows likewise that Life is not a presupposition in the empirical sense that in order to be a self-conscious being one needs to be a living being, but in the logical sense that self-consciousness relates to the kind of object that is the logical ground for its own constitution.

$\mathrm{Ng}$ delivers a very sophisticated and highly plausible explication of these claims, and along these lines it is plausible to argue that 'the key to understanding this scandalous chapter [the chapter of the Idea of Life, K.K.] lies not in the details of its contents, $[\ldots]$, but more importantly in understanding the specific status and function that Hegel is attributing to life in the logical context' (255).

I understand Ng's Hegelian argument that inner purposiveness is a constitutive concept and therefore against Kant's claim of the only regulative status of 


\section{Purposiveness, Intelligibility and Scepticism}

purposiveness, to be twofold: inner purposiveness is the primary conception of purposiveness, since only Life provides 'Gattung'-concepts and with them the schema of genus-species-kind relations (166, fn2). However, the first argument that shows Life to be the primary conception of purposiveness does not entail as such that Life also has to be understood as constitutive. Life could be understood as the primary conception of purposiveness but still on a regulative basis. It only entails the claim of Life being constitutive if one also claims that Life is a necessary condition for self-consciousness ${ }^{9}$ and it is specifically the introduction of the speculative-identity thesis that shall do this job. This thesis entails that inner purposiveness is constitutive because it is a necessary condition for selfconsciousness. In the Logic, $\mathrm{Ng}$ takes this claim to be reflected in Hegel's thesis that Life is a presupposition for self-consciousness that is to be interpreted as a doubling of the Idea $(104,274)$.

However, even if $\mathrm{Ng}$ provides plausible reasons to grant such a logical role to Life in Hegel, it is not immediately obvious that Ng's Hegel really has a rejoinder to Kant's scepticism with respect to natural purposiveness being constitutive. For, according to $\mathrm{Ng}$

Hegel tries to address Kant's skepticism with respect to inner purposiveness directly [...]. Hegel tries to tackle Kant's question quid juris: By what right do we employ the concept of life, or the principle of purposiveness, in our activities of judgment? Hegel transforms Kant's Copernican Revolution not by presenting life as a category among others in a metaphysical deduction but, rather, by arguing for its constitutive character, inserting it into our concept of self-consciousness and reconceiving the structure of experience according to the internal relation between self-consciousness and life. [...] The unity of the objects of experience afforded by the unity of self-consciousness is thus thoroughly underwritten by the concept of life as a matter of a priori necessity which allows Hegel to argue, contra Kant, that inner purposiveness has constitutive status (111).

However, my worry is that this response is actually not a direct answer to Kant's scepticism. Thus, showing Life to be a necessary condition for self-consciousness does not provide a rejoinder to Kantian scepticism. For, Kant's scepticism towards natural purposiveness is not anchored in the question whether Life is a necessary condition for self-consciousness or not; it rather stems from two objections, concerning the relation between purposive causality and mechanism, and these objections are not resolved by the arguments given so far: it stems from the backward causation objection and the mereological problem. 


\section{Karen Koch}

According to the first objection, natural purposiveness would pervert the nexus of cause and effect because, in purposive relations, a thing is both an effect and a cause of the same thing of which it is the effect. Thus, in contrast to the linearity of the sequence of cause and effect, in purposive causality, the end for the sake of which the causal relation takes place represents the cause of the whole causal process, and likewise, the end represents the effect that shall be attained. According to the second objection, the mereological one, nature is subject to principles according to which parts are constitutive of wholes. In the case of purposive causality however, the form and actuality of parts are grounded in the whole. Thus, there is a logical grounding relation that goes in the opposite logical direction.

Now, Kant's subjective, regulative account of purposiveness avoids these objections. If an end must be represented through an understanding before being realized, purposive causality does not pervert the order of nature. For the end that shall be attained is not a real cause in nature but ideal, i.e. a representation of the end that is to be achieved. Likewise, the whole in which its parts are grounded is not a real whole but an ideal representation.

Now, it seems also clear to me that Hegel buys the essential features of the Kantian conception of mechanism that evoke this kind of objections in first place. First, according to Hegel a cause sublates into the effect (WL: 160f./ $12: 155)$ - it has 'actuality only [...] in the effects, [...] [its] activity is a transition' (WL: 657/12:160). In this transition, a cause does not maintain itself, it rather is transformed into the effect. A purpose however does not sublate into its means but reproduces itself by its means, therefore, a purpose is 'exempt from transition' (WL: 657, 12:160). Thus, there is a linear order within a sequence of cause and effect, whereas purposive causality consists in a direct reciprocity between means and purpose. Along these lines Hegel claims that

a purpose can be also defined [...] as a cause but these expressions cover only an incomplete side of its signification; if they are to be said of purpose according to its truth, this can be done only in a way that sublates their concept-as a cause that solicits itself to expression, or a cause that is a cause of itself or whose effect is immediately the cause (WL: 657/12:160).

Thus, Hegel argues that describing purposive causality in terms of efficient causality undermines the very concept of efficient causality. It is the thesis of the linear order of cause-and-effect that provokes the backward causation objection.

The other feature of mechanism according to which wholes are constituted by their parts does also apply in Hegel's account of mechanism: 'The mechanical relationship, in its superficial form, consists generally in the fact that the parts are taken as self-sufficient opposite one another and opposite the whole' (EL: \$136R/ $20: 160)$. In the beginning of the mechanism chapter, Hegel characterizes 
mechanical objects as aggregates precisely because the parts of an object are selfsufficient and only stick together because they are subject to a force being external to them. In contrast to that, in a purposive unity all processes take place for the sake of preserving the parts of that unity and therefore for preserving that unity itself. The parts of a unity according to inner purposiveness are not self-sufficient on their own, they do not even come to existence on their own; they exist 'only in the individuality' (WL: 681/12:184) of the purposive unity. Thus, in purposive causality, the grounding relation between parts and whole goes in the opposite direction, which in turn evokes the mereological problem.

Consequently, Hegel must have a rejoinder to these objections in order to reply to the Kantian scepticism. Neither the argument of life opening the space of reasons, nor the further developed argument of life being constitutive for selfconsciousness are addressing the reasons for Kant's scepticism. Therefore, I think there remains an open question regarding the status of inner purposiveness. The question that remains is how the conceptual structures of efficient causality and mechanism relate to teleology and especially to the conception of inner purposiveness, respectively. Hegel needs an argument showing that these objections do not apply. Now, my suggestion is that an answer to this question lies exactly in the details of the contents of the Idea of Life, and especially in the relation of this content to the structure of mechanism, and along these lines, Hegel has been read by scholars. ${ }^{10}$ Thus, I think that Ng's argument for inner purposiveness being constitutive needs to be expanded by the inclusion of a direct rejoinder to these objections.

Hegel's Concept of Life is a fascinating achievement. It offers a refreshingly and illuminating account of the logical role of Life within the Logic. As such, it should not be missed by anyone interested in Hegel's philosophy and especially in his account of Life. ${ }^{11}$

\section{Karen Koch \\ Freie Universität Berlin, Germany \\ karenkoch@zedat.fu-berlin.de}

\section{Notes}

${ }^{1}$ I capitalize 'Life' as well as other notions important in Hegel's philosophy when referring to Hegel's technical use of them.

2 Cf. Düsing 1986: 281-88; Taylor 1975: 332-34.

${ }^{3}$ It should be noted that $\mathrm{Ng}$ discusses the other approaches only in the introduction to her book (10-16). She does not come back to these approaches within the course of the book.

4 Abbreviations used 


\section{Karen Koch}

CJ = Kant, Critique of the Power of Judgment, trans. P. Guyer and E. Matthews (Cambridge, Cambridge University Press, 2000)/Kritik der Urteilskraft, ed. H. F. Klemme (Hamburg: Meiner, 2009).

$\mathrm{EE}=$ Kant, First Introduction to the Critique of the Power of Judgement, trans. P. Guyer and E. Matthews (Cambridge: Cambridge University Press, 2000)/Erste Einleitung in die Kritik der Urteilskraft (Hamburg: Meiner 2000).

EL = Hegel, Encyclopedia of Philosophical Sciences in Basic Outline. Part 1: Science of Logic, trans. K. Brinkmann and D. O. Dahlstrom (Cambridge: Cambridge University Press, 2010)/Enzyklopädie der philosophischen Wissenschaften im Grundrisse (1830), ed. W. Bonsiepen and H. C. Lucas, Gesammelte Werke 20 (Hamburg: Meiner, 1992).

$W L=$ Hegel, Science of Logic, trans. G. di Giovanni (Cambridge: Cambridge University Press, 2010)/Wissenschaft der Logik. Zweiter Band. Die subjektive Logik (1816), ed. F. Hogemann and W. Jaeschke, Gesammelte Werke 12 (Hamburg: Meiner, 1981).

${ }^{5}$ Her thesis that Hegel transforms the Kantian Copernican Revolution by thinking Life as constitutive for self-consciousness, but exactly not in the sense of a category (111), might suggest that on her account, the apperception view is dismissed.

${ }^{6} \mathrm{Ng}$ notes that Hegel claims that nature is living indeed, however, according to her, the Logic is about the 'legitimate and lawful employment of the concept of life' asking '[b]y what right can we employ the concept of life in a constitutive, objective manner?', and not about whether or not there is life in nature in fact (7).

${ }^{7} \mathrm{Ng}$ argues that 'that internal purposiveness is the primary sense of purposiveness that opens up the horizon of intelligibility and judgment' (44). To be clear, $\mathrm{Ng}$ does not claim that Kant has actually taken this path, but she suggests that Kant considered it and that this path is then in fact taken up by Hegel and elaborated on in his Subjective Logic (50).

${ }^{8}$ Friedman and Guyer for example argue that the regularity of nature is established by the Transcendental Analytic. Friedman (1992). Guyer 1987: 237-666 and Guyer 2017.

${ }^{9} \mathrm{Ng}$ argues that this claim is also already an issue in Kant, in so far as she thinks that 'Kant's theory of judgment [as established in the first Critique, K.K.] remains radically incomplete without a consideration of this theme [the purposiveness theme, K.K.]' (62). This at least suggests that it also already affects the constitution of self-consciousness itself in Kant.

${ }^{10}$ Kreines 2015: 81-97. Lindquist (2018). It must be noted, however, that there is a debate about which challenge Hegel really responds to - to the backward causation objection or to the mereological objection. Whereas Kreines reads Hegel as responding to the backward causation objection, Lindquist argues that Hegel needs to respond to the mereological problem. This debate depends on the reading of the Kantian passages. I side with Zuckert's reading here, that actually both objections apply in Kant; cf. Zuckert (2017), 275f. If this is correct, and if Hegel buys the essential features of Kant's conception of Mechanism that evoke these objections, then Hegel needs a rejoinder to both objections.

11 Thanks to Mihnea Chiujdea, Dina Emundts and Mathis Koschel for commenting on the first draft of this paper. 


\section{Purposiveness, Intelligibility and Scepticism}

\section{Bibliography}

Düsing, K. (1986), 'Die Idee des Lebens in Hegels Logik', in R.-P. Horstmann and M. J. Petry (eds.), Hegels Philosophie der Natur: Beziehungen zwischen empirischer und spekulativer Naturerkenntnis. Stuttgart: Klett-Cotta.

Friedman, M. (1992), 'Causal Laws and the Foundation of Natural Science', in P. Guyer (ed.), The Cambridge Companion to Kant. Cambridge: Cambridge University Press.

Guyer, P. (1987), Kant and the Claims of Knowledge. Cambridge: Cambridge University Press.

Guyer, P. (2017), 'Imperfect Knowledge of Nature. Kant, Hume, and Laws of Nature', in M. Massimi and A. Breitenbach (eds.), Kant and the Laws of Nature. Cambridge: Cambridge University Press.

Kreines, J. (2015), Reason in the World. Oxford: Oxford University Press.

Lindquist, Daniel (2018), 'Hegel's "Idea of Life" and Internal Purposiveness', HOPOS. The Journal of the International Society of Philosophy of History, 8:2, 376-408. Taylor, C. (1975), Hegel. Cambridge: Cambridge University Press.

Zuckert, R. (2007), 'Organism and System in German Idealism', in K. Ameriks (ed.), The Cambridge Companion to German Idealism. Cambridge: Cambridge University Press. 